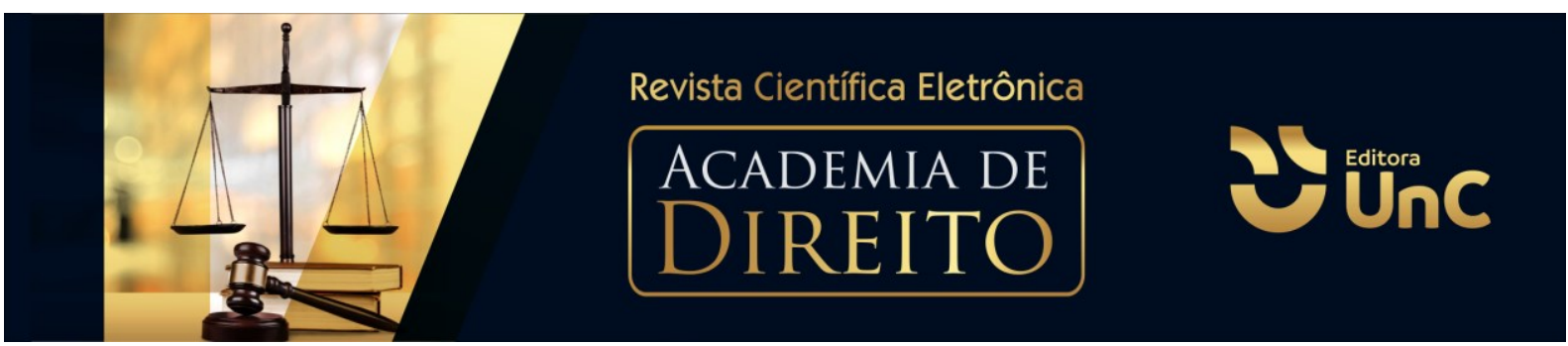

\title{
O PODER DE POLÍCIA EXERCIDO PELO CORPO DE BOMBEIROS MILITAR DE MAFRA NA REGULARIZAÇÃO DAS EDIFICAÇÕES
}

\section{THE POLICE POWER EXERCISED BY THE MILITARY FIREFIGHTER BODY OF MAFRA IN REGULATING BUILDINGS}

Adriano José Marciniak ${ }^{1}$

Vlademir Vilanova Moreira ${ }^{2}$

\begin{abstract}
RESUMO
O presente artigo tem por objetivo analisar a aplicação da Lei n. 16.157, de 07 de novembro de 2013, que concedeu o Poder de polícia ao Corpo de Bombeiros Militar de Santa Catarina na regularização de edificações na cidade de Mafra/SC. Para tanto, inicialmente faz uma abordagem histórica elencado que a referida norma trouxe enormes mudanças nos quesitos relativos aos sistemas preventivos contra incêndio e pânico. Infelizmente as mudanças normativas ocorreram em virtude de tragédias ocorridas onde inúmeras pessoas perderam suas vidas a exemplo do incêndio na Boate Kiss, em Santa Maria/RS. Momento posterior, de posse de dados obtidos a partir do acesso a sistemas do CBMSC, pôde-se acessar um vasto campo de dados e coletar informações relevantes para proporcionar uma análise fidedigna no que tange a vigência da norma e sua real aplicação. Analisam-se ainda decisões proferidas pelo Tribunal de Justiça de Santa Catarina o qual tem corroborado no sentido de manter as exigências estabelecidas pelo Corpo de Bombeiros Militar relacionas a sistemas preventivos contra incêndio e pânico. Essa construção, por meio da metodologia monográfica com abordagem dedutiva, e técnicas de pesquisa bibliográfica indireta realizada por meio de documentação secundária, com base na legislação vigente, doutrina, jurisprudência dos tribunais informativos e arquivos do Corpo de Bombeiros Militar de Santa Catarina, permite concluir, ao final, que o Poder de Polícia exercido pelo CBMSC na cidade de Mafra tem contribuído positivamente proporcionando maior segurança às pessoas que de modo geral utilizam as edificações.
\end{abstract}

Palavras-Chave: Medidas de polícia administrativa. Segurança Contra Incêndio e Pânico. Corpo de Bombeiros. Instruções Normativas.

\footnotetext{
${ }^{1}$ Graduação em Direito, Universidade do Contestado (UnC). Campus Mafra. Santa Catarina. Brasil. E-mail: adrianomarciniak@gmail.com.

${ }^{2}$ Mestre em Ciências Jurídicas, Universidade do Contestado (UnC). Campus Mafra. Santa Catarina. Brasil. E-mail: vlademir.moreira@professor.unc.br.
} 


\begin{abstract}
This article aims to analyze the application of Law no. 16,157, of November 7, 2013, which granted police power to the Military Fire Brigade of Santa Catarina in the regularization of buildings in the city of Mafra/SC. To this end, it initially takes a historical approach, which mentioned that this rule brought huge changes in the requirements related to preventive systems against fire and panic. Unfortunately, the normative changes occurred due to the tragedies that occurred where countless people lost their lives like the fire at Boate Kiss, in Santa Maria / RS. Later, with data obtained from access to CBMSC systems, it was possible to access a vast field of data and collect relevant information to provide a reliable analysis regarding the validity of the standard and its actual application. The decisions handed down by the Santa Catarina Court of Justice have also been analyzed in order to maintain the requirements established by the Military Fire Brigade relating to preventive systems against fire and panic. This construction, through the monographic methodology with a deductive approach, and indirect bibliographic research techniques carried out through secondary documentation, based on the current legislation, doctrine, jurisprudence of the informational courts and archives of the Military Fire Brigade of Santa Catarina, allows to conclude, in the end, that the Police Power exercised by the CBMSC in the city of Mafra has contributed positively by providing greater security to people who generally use the buildings.
\end{abstract}

Keywords: Administrative police measures. Fire and Panic Safety. Fire Department. Normative Instructions.

\title{
1 INTRODUÇÃO
}

O presente estudo aborda, em linhas gerais, o que pretende ser uma moderna concepção da Lei do poder de polícia do Corpo de Bombeiros Militar de Santa Catarina, sob a perspectiva da regularização das edificações da cidade de Mafra, desde a entrada em vigor da Lei n. 16.157, de 7 de novembro de 2013.

O ponto de partida, portanto, está na natureza restritiva de direitos de que se reveste o instituto, apresentado pela Lei n. 16.157, de 7 de novembro de 2013, que dispõe sobre as normas e os requisitos mínimos para a prevenção e segurança contra incêndio e pânico e o Decreto n. 1957 de 20 de dezembro de 2013, que regulamenta a Lei n. 16.157, de 2013.

Corroboram ainda para elucidar o referido tema a Lei n. 13.425 , de 30 de março de 2017, que estabelece diretrizes gerais sobre medidas de prevenção e combate a incêndio e a desastres em estabelecimentos, edificações e áreas de reunião de público; que altera as Leis n. 8.078, de 11 de setembro de 1990, e 
10.406, de 10 de janeiro de 2002 - Código Civil e as Instruções Normativas do Corpo de Bombeiros Militar de Santa Catarina.

O incêndio ocorrido na boate Kiss na cidade de Santa Maria - Rio Grande do Sul, em 2013, se apresenta como um importante marco no ordenamento jurídico brasileiro. A referida tragédia impulsionou a criação da Lei estadual SC n 16.157 , de 7 de novembro de 2013, que estabeleceu diretrizes gerais e ações complementares para a segurança contra incêndio e pânico em estabelecimentos comerciais, em edificações e áreas de reunião de público.

O setor do Corpo de Bombeiros Militar responsável pela análise de projetos, vistorias e infrações é denominado de Serviço de Segurança Contra Incêndio e Pânico (SSCI), seção diretamente ligada a concessão do Poder de Polícia Administrativa ao Corpo de Bombeiros Militar de Santa Catarina (CBMSC).

A inexistência de pesquisas acadêmicas a respeito da análise do poder de polícia exercido pelo Corpo de Bombeiros Militar de Mafra, motiva a elaboração do estudo do referido tema.

Tal assunto se reveste de importância uma vez que trata diretamente dos direitos individuais e coletivos.

Nesse contexto se posiciona Lazzarini (1999, p. 129):

\begin{abstract}
A atividade-fim dos Corpos de Bombeiros Militares é a de prevenção e combate a incêndios. Busca e salvamento e, agora, a de defesa civil, prevista no art. $144, \S 5^{\circ}$, final. Essa gama de atribuições dos Corpos de Bombeiros Militares diz respeito, isto sim, à tranquilidade pública e, também, à salubridade pública, ambas integrantes do conceito de ordem pública.
\end{abstract}

Dessa forma, se observa a inclusão no rol das atribuições do Corpo de Bombeiros as atividades relacionadas com defesa civil. Além das já previstas anteriormente sendo elas: Combate a Incêndio, Atendimentos Pré-Hospitalar busca e salvamento. Cabe destacar que todas as atribuições têm por objetivo manter a organização Pública.

\title{
2 DO PODER DE POLÍCIA
}

Juntamente com os serviços públicos e as atividades de fomento, o poder de polícia constitui uma das três funções precípuas da Administração Pública moderna. 
Poder de Polícia, Prestação de Serviços, Realização de atividades de Fomento. (MAZZA, 2018, p. 432).

A palavra polícia origina se do grego politeia, e do latim politia, ligado com o termo política, ao vocábulo polis sendo utilizado para designar todas as atividades da cidade-estado.

Os serviços públicos em regra são oferecidos para proporcionar vantagens aos indivíduos e a coletividade. O poder de Polícia se apresenta com um conceito contrário onde seu principal foco é a restrição de direitos. "O poder de polícia, pelo contrário, representa uma atividade estatal restritiva dos interesses privados, limitando a liberdade e a propriedade individual em favor do interesse público" (MAZZA, 2018, p. 432). Dessa foram observa-se que os interesses da coletividade prevalecem sobre os interesses individuais.

\begin{abstract}
O poder de polícia não se reduz à atuação estatal de oferecimento de segurança pública. É que as instituições públicas encarregadas desse mister herdaram o nome da atividade, sendo conhecidas como "polícias". Porém, a noção de poder de polícia é bem mais abrangente do que o combate à criminalidade, englobando, na verdade, quaisquer atividades estatais de fiscalização. Desse modo, vigilância sanitária e fiscalização de trânsito são exemplos de manifestação do poder de polícia sem qualquer relação com a segurança pública. Por isso, as polícias civil, militar e federal exercem o poder de polícia; mas este não se esgota na atividade específica de manter a segurança pública (MAZZA, 2018, p. 433).
\end{abstract}

Nesse sentido também se posiciona Meirelles (2002, p. 128): "O Poder de Polícia é, em suma, o conjunto de atribuições concedidas a Administração para disciplinar e restringir, em favor do interesse público adequando, direitos e liberdades individuais".

Ao encontro do posicionamento dos doutrinadores já mencionados Nohara (2019, p. 141):

\footnotetext{
Em sentido vulgar, a palavra polícia no Brasil é associada mais comumente à corporação encarregada de zelar pela preservação da ordem e da segurança pública. Contudo, do ponto de vista do Direito Administrativo, poder de polícia possui significado mais amplo, consistente na atividade de condicionar e restringir o exercício dos direitos individuais, tais como a propriedade e a liberdade, em benefício do interesse público.
}

No direito brasileiro, encontra-se conceito legal de poder de polícia no artigo 78 do Código Tributário Nacional (Lei n 5.172, de 25/10/1966), que dispõe: 
Considera-se poder de polícia a atividade da administração pública que, limitando ou disciplinando direito, interesse ou liberdade, regula a prática de ato ou abstenção de fato, em razão de interesse público concernente à segurança, à higiene, à ordem, aos costumes, à disciplina da produção e do mercado, ao exercício de atividades econômicas dependentes de concessão ou autorização do Poder Público, à tranquilidade pública ou ao respeito à propriedade e aos direitos individuais ou coletivos. Parágrafo único: Considera-se regular o exercício do poder de polícia quando desempenhado pelo órgão competente nos limites da Lei aplicável, com observância do processo legal e, tratando-se atividade que a Lei tenha como discricionária, sem abuso ou desvio de poder (BRASIL, 1966).

O Poder de Polícia em sentido amplo se caracteriza como um conceito mais abrangente relacionados a restrições legislativas e limitações administrativas "Em sentido amplo, poder de polícia é entendido como a atividade estatal de condicionar a liberdade e a propriedade, ajustando-as aos interesses coletivos (MELLO, 2008, p. 838).

Pode ser defino como uma ação do Estado que restringe direitos individuais em prol do interesse da coletividade, efetivado mediante criação de leis.

Para Carvalho Filho (2019, p. 77) o poder de polícia em sentido amplo pode ser definido como:

[...] toda e qualquer ação restritiva do Estado em relação aos direitos individuais. Sobreleva nesse enfoque a função do Poder Legislativo, incumbido da criação do ius novum, e isso porque apenas as Leis, organicamente consideradas, podem delinear o perfil dos direitos, elastecendo ou reduzindo o seu conteúdo. É princípio constitucional o de que 'ninguém será obrigado a fazer ou deixar de fazer alguma coisa senão em virtude de Lei' (art. $5^{\circ}, \mathrm{II}, \mathrm{CF}$ ).

De uma forma mais específica o Poder de Polícia em sentido estrito é mais citado pela doutrina uma vez que trata somente das limitações administrativas impostas as propriedades privadas, não referenciando dispositivos legais.

Ainda nesse sentido, o poder de polícia se configura como atividade administrativa, que consubstancia, como vimos, verdadeira prerrogativa conferida aos agentes da Administração, consistente no poder de restringir e condicionar a liberdade e a propriedade (CARVALHO FILHO, 2019, p. 78).

De forma geral pode-se observar que em uma comparação dos principais doutrinadores as ideias apresentadas se convergem para um ponto em comum "a supremacia do interesse público perante o privado, através de ações fiscalizadoras e coercitivas" (MAZZA, 2018, p. 433). 
A atuação do estado no que tange ao Poder de Polícia é baseado na Lei e no domínio, proporcionando limitações a particulares e a propriedade.

Poder de polícia é a atividade da Administração Pública, baseada na Lei e na supremacia geral, consistente no estabelecimento de limitações à liberdade e propriedade dos particulares, regulando a prática de ato ou a abstenção de fato, manifestando-se por meio de atos normativos ou concretos, em benefício do interesse público (MAZZA, 2018, p. 435).

De nossa parte, entendemos se possa conceituar o poder de polícia como a prerrogativa de direito público que, calcada na Lei, autoriza a Administração Pública a restringir o uso e o gozo da liberdade e da propriedade em favor do interesse da coletividade (CARVALHO FILHO, 2019, p. 78).

A polícia administrativa inicialmente fica restringida a relação direta com a restrição de direitos individuais em prol da segurança da coletividade, porém se o estado é responsável não apenas pela segurança e sim pelas questões ambientais e econômicas, pode-se então observar uma amplitude de sua aplicação, não ficando restringido apenas no que tange a segurança.

A polícia administrativa passa a compreender não apenas a segurança, mas também a moral, a saúde, o meio ambiente, a defesa do consumidor, a propriedade e o patrimônio cultural, o que gera a necessidade de criação de polícias especializadas, tais como as de: segurança, meio ambiente, aérea, marítima, aeroportuária, sanitária e de defesa civil (NOHARA, 2019, p. 144).

O Poder de Polícia administrativa pode ser visto como uma atividade completa dentro da administração onde seu ciclo inicia e finda-se no âmbito da função administrativa, fator que diferencia da Polícia Judiciária, a qual inicia seu ciclo dentro da administração porém serve como uma preparação para o prosseguimento na função jurisdicional penal.

A Polícia Administrativa é atividade da Administração que se exaure em si mesma, ou seja, inicia e se completa no âmbito da função administrativa. $O$ mesmo não ocorre com a Polícia Judiciária, que, embora seja atividade administrativa, prepara a atuação da função jurisdicional penal, o que a faz regulada pelo Código de Processo Penal (arts. $4^{\circ} \mathrm{ss}$ ) e executada por órgãos de segurança (polícia civil ou militar), ao passo que a Polícia Administrativa o é por órgãos administrativos de caráter mais fiscalizador (CARVALHO FILHO, 2019, p. 85). 
Conforme Nohara (2019), podem ser mencionadas como manifestação de atividades de poder de polícia num Estado intervencionista, no qual o Estado controla e restringe não apenas questões voltadas à segurança de pessoas e bens, mas também atua, por exemplo:

\begin{abstract}
Concessão de alvará de licença ou de autorização para realização de atividades comerciais, como a licença para efetivar o direito de construir, que envolve a polícia edilícia ou das edificações (construções);determinação da localização e do horário de funcionamento de atividades comerciais no Município, sendo conteúdo da Súmula Vinculante 38, que 'é competente o Município para fixar o funcionamento de estabelecimento comercial'- delimitação e verificação de condições sanitárias em estabelecimentos e nos produtos vendidos, em inúmeros setores tais como: o higiênico, o alimentício, o ecológico, o zoos sanitário, o fitossanitário e até, mais recentemente, conforme enfatiza Diogo de Figueiredo Moreira Neto, o genético;- controle dos medicamentos;- estipulação de regras e fiscalização da poluição sonora, visual ou atmosférica;- controle da produção e mercado, em âmbito da concorrência;- determinação e fiscalização de atividades bancárias; - fiscalização do trânsito;- determinação e fiscalização ambiental; e - controle do exercício das profissões (NOHARA, 2019, p. 146).
\end{abstract}

No rol exemplificativo apresentado ao encontro do que se refere a segurança da coletividade podemos associar tal instituto ao que concede alvará de construção, licença ou autorização para a realização de atividades comerciais, no que tange a segurança contra incêndio e pânico.

\title{
3 O SERVIÇO DE SEGURANÇA CONTRA INCÊNDIO E PÂNICO NOS CORPOS DE BOMBEIROS MILITARES
}

A Atividade Técnica é um conjunto de medidas desenvolvidas para garantir a segurança contra incêndio e pânico desenvolvida por meio de instalação de equipamentos que auxiliam o abandono das pessoas do local sinistrado.

Registra-se no Brasil como sendo o primeiro sinistro de grande vulto o incêndio ocorrido no Gran Circus-Norte Americano, instalado na cidade do Rio de Janeiro- RJ, no ano de 1961, o qual incendiou e levou a óbito mais de 500 (quinhentas pessoas).

A década de 70 do século $X X$ representou um marco na mudança das atividades de bombeiros em todo o Brasil, os sinistros incêndios registrados na capital paulistana em fevereiro de 72 e 74 , nos edifícios Andraus e Joelma, 
respectivamente (CARDOSO, 2014, p. 44). Nesses sinistros envolvendo edificações verticalizadas de ocupação multifamiliar, morreram cerca de 114 (cento e quatorze) pessoas e mais de 775 (setecentos e setenta e cinco) ficaram feridas.

Com os referidos sinistros observa-se a necessidade de reanálise da legislação pertinente a fiscalização por parte dos Corpos de Bombeiros, falhas preventivas foram observadas e necessitavam ser corrigidas para evitar que outros desastres se desencadeassem.

Praticamente vinte e nove anos após o ocorrido em São Paulo, vem à tona o incêndio em uma casa de show "Boate Kiss" localizada na cidade de Santa MariaRS. O sinistro ficou marcado pelo grande número de mortos que totalizaram 242 (duzentos e quarenta e dois) e deixou mais de 600 feridos.

$O$ incêndio iniciou no palco da boate e o isolamento acústico utilizado na casa de shows facilitou a propagação rápida das chamas, bem como o material do referido revestimento era tóxico o que colaborou par ao elevado número de vítimas.

A repercussão do sinistro em Santa Maria repercutiu em todo território nacional, o que levou os Corpos de bombeiros a refletir de forma geral sobre a legislação vigente.

\subsection{ORGANIZAÇÃO DO SERVIÇO DE SEGURANÇA CONTRA INCÊNDIO (SSCI)}

A SSCI tem como função primordial supervisionar se as normas provenientes da Diretoria de Segurança contra Incêndio (DSCl) e Comando Geral são cumpridas pelas edificações instaladas em suas jurisdições. Essa conferência é realizada, de modo geral, nas três etapas de regularização de um imóvel: Análise do Projeto Preventivo Contra Incêndio e Pânico (PPCl), vistoria de habite-se e vistoria de funcionamento.

De acordo com 0 art $7^{\circ}$ da Instrução Normativa 01 podemos elencar as principais funções das SSCls:

\footnotetext{
- supervisão do cumprimento das disposições legais baixadas pela DAT;

- análise de Projeto Preventivo Contra Incêndio (PPCI);

- vistoria de imóveis (edificações, estruturas, áreas de risco e eventos transitórios);

- supervisão da rede pública de hidrantes;
} 
- expedição de atestados de aprovação referentes à vistoria e análise do $\mathrm{PPCl}$;

- aplicação de sanções previstas em Lei pelo descumprimento das Normas de Segurança Contra Incêndio e Pânico (SANTA CATARINA, 2019a. p. 05).

$\mathrm{Na}$ atual conjuntura organizacional do CBMSC não é obrigatório uma estrutura padrão da SSCls, porém sugere-se que algumas funções chaves estejam presentes, com o objetivo de proporcionar um bom funcionamento.

Contudo, para que toda SAT tenha um bom funcionamento, deve possuir áreas com incumbências específicas, nas quais as atribuições de cada área podem ser realizadas por bombeiros exclusivos e especializados em determinados temas [...] Independente da estrutura adotada, toda SAT possui pelo menos cinco áreas com atividades bem definidas: Protocolo, Análise, Vistoria, Cartório e Chefia, responsáveis por tarefas específicas (SANTA CATARINA, 2019a, p. 13).

A SSCI possui 06 (seis) principais funções distribuídas de acordo com o fluxograma de organização funcional (SANTA CATARINA, 2019a):

Figura 1 - Organograma das Atividades desenvolvidas pela SSCI.

Organização da SSCl

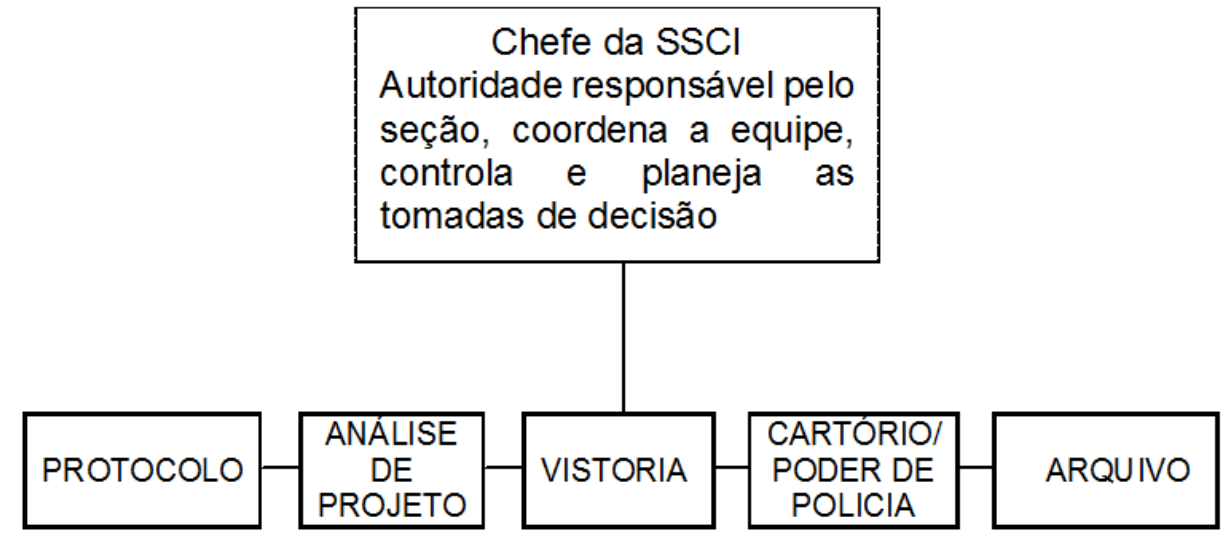

Fonte: Santa Catarina (2019a)

Para melhor compreensão vale destacar as seguintes funções, Protocolo é o responsável pelo atendimento direto ao público, recebimento da demanda de vistorias, agendamentos e fornecimento de atestados, organiza os arquivos. A análise é o setor que confere os Projetos Preventivos apresentados pelos responsáveis técnicos, observa se estão de acordo com a legislação em vigor, ou seja, se atendem as exigências das Instruções Normativas. 
A vistoria é um trabalho desenvolvido em campo, onde o militar realiza a conferência dos sistemas instalados nas edificações, bem como se os mesmos foram executados de acordo com o PPCl aprovado.

O cartório é o setor responsável pelo controle de prazos dos documentos inerentes ao poder de polícia administrativo exercido pelo CBMSC, recebe os documentos organiza os processos administrativos e mantém o chefe da Seção informado sobre a situação de cada edificação. O Chefe do Serviço de Segurança Contra Incêndio e Pânico é o responsável pela gestão, e possui as seguintes funções de acordo com a Diretriz Operacional 26/CBMSC:

a) supervisão do cumprimento das disposições legais baixadas pela DSCl; b) análise, no mínimo uma vez por semana de projetos preventivos contra incêndio de alta complexidade; c) vistoria, no mínimo uma vez por semana, imóveis de alta complexidade; d) atendimento aos profissionais e retorno às consultas técnicas do $\mathrm{SSCl}$, antes de encaminhar à DSCl; e) inspeção das SSCls; f) análise dos relatórios de indeferimento das análises e das vistorias (por amostragem); g) planejamento das atividades técnicas (férias e outros afastamentos, produção individual e geral de análise e vistorias, vistorias em municípios onde não possui uma OBM/GBM) no mês de dezembro de cada ano. Deve encaminhar uma cópia do planejamento assinado pelo comandante da OBM, na primeira semana do mês de fevereiro a DSCl; h) fiscalização de cumprimento das metas do planejamento; i) fiscalização de prazos para a realização de análise de $\mathrm{PPCl}$ e vistorias; j) fiscalização das condições técnicas e operacionais para a realização da atividade técnica; $k$ ) atualização do registro das condições operacionais da rede pública de hidrantes, para emprego pelas guarnições de serviço; I) zelo pelo cumprimento das NSCI (Diretriz Operacional 26. SANTA CATARINA, 2017, p. 10).

Em 07 de novembro de 2013, cerca de nove meses após o sinistro, entrou em vigor a Lei n. 16.157/13, que concedeu o poder de polícia ao Corpo de Bombeiros Militar de Santa Catarina, com o objetivo de fiscalizar as edificações e promoções de eventos.

Art. $1^{\circ}$ Esta Lei institui as normas e os requisitos mínimos para a prevenção e segurança contra incêndio e pânico em imóveis localizados no Estado, com o objetivo de resguardar a vida das pessoas e reduzir danos ao meio ambiente e ao patrimônio, nos casos de: I - regularização das edificações, estruturas e áreas de risco; II - construção; III - mudança da ocupação ou do uso; IV - reforma e/ou alteração de área e de edificação; e V - promoção de eventos. Parágrafo único. O disposto nesta Lei não se aplica às edificações residenciais unifamiliares (SANTA CATARINA, Lei estadual 16.157/13, 2017). 
Cabe ressaltar que a referida Lei deixa de manter sob responsabilidade do Corpo de Bombeiros Militar de Santa Catarina, as edificações Unifamiliares, ou seja, aquelas de uso exclusivo de uma única família (casa).

Atualmente, para uma edificação ser construída e estar plena com suas obrigações legais, necessita possuir atestados de funcionamento de órgãos da administração federal, estadual e municipal. De acordo com a referida Lei 16.157/13, o fornecimento de atestados pelo município fica vinculado a apresentação da apresentação do atestado fornecido pelo CBMSC (Corpo de Bombeiros Militar) "Art. $2^{\circ}$ A concessão de alvará de construção, de habite-se ou de funcionamento pelos Municípios fica condicionada ao cumprimento desta Lei, observados também outros requisitos previstos na legislação municipal, estadual ou federal”.

\section{O PODER DE POLÍCIA EXERCIDO PELO CORPO DE BOMBEIROS MILITAR NA CIDADE DE MAFRA-SC}

A lei que concedeu o Poder de Polícia ao Corpo de Bombeiros Militar de Santa Catarina é recente, Lei n. 16.157, de novembro de 2013. Regulamentada pelo Decreto n. 1957 de 20 de dezembro de 2013. Com praticamente 7 (sete) anos de vigência.

A efetividade da uma norma pode ser entendida como "o princípio da [...] efetividade das normas constitucionais deve ser entendido no sentido de a norma constitucional ter a mais ampla efetividade social” (LENZA, 2019, p. 177).

Podemos considerar efetiva a lei que desempenha de forma completa sua função social, que é respeitada e atinge seus objetivos consegue estabelecer a sintonia entre as responsabilidades da sociedade e a exigência da norma.

a efetividade significa, portanto, a realização do Direito, o desempenho concreto de sua função social. Ela representa a materialização dos fatos, dos preceitos legais e simboliza a aproximação, tão íntima quanto possível, entre o dever-ser normativo e o ser da realidade social (BARROSO, 1993, p. 79).

O corpo de Bombeiros Militar, possui suas Instruções Normativas (INs) elaboradas com base na própria lei que concede o Poder de Polícia, com base nas INs são realizados os procedimentos para emissão de atestados de Aprovação de 
Projeto, Habite-se e Funcionamento e na sua função fiscalizadora pode vistoriar imóveis bem como solicitar documentação para comprovação de informações "Art. 13 O CBMSC pode, quando investido em sua função fiscalizadora, observadas as formalidades legais, vistoriar qualquer imóvel, bem como solicitar documentos relacionados com as NSCI." (art. 13. IN 01 SANTA CATARINA, 2019a).

Cada Instrução Normativa é voltada para apresenta as exigências mínimas de cada sistema preventivo, atualmente o CBMSC possui 35 INs em vigor:

\begin{abstract}
IN 01 procedimentos administrativos: processos gerais de segurança contra incêndio e pânico- parte 1 e 2, IN 02 infrações administrativas, IN 03 carga de incêndio, IN 04 terminologia de segurança contra incêndio, IN 05 edificações existentes, IN 06 sistema preventivo por extintores, IN 07 sistema hidráulico preventivo, IN 08 instalações de gás combustível (glp \& gn), IN 09 sistema de saída de emergência, IN 09 sistema de saída de emergência - vigente a partir de 31/07/2020, IN 10 revogada(revogada),IN 11 sistema de iluminação de emergência, IN 12 sistema de alarme e detecção de incêndio, IN 13 sinalização para abandono de local, IN 14 compartimentação, tempo de resistência ao fogo e isolamento de risco ,IN 15 sistema de chuveiros automáticos (sprinklers), IN 16 sistema fixo de gases limpos e dióxido de carbono $\left(\mathrm{CO}^{2}\right)$, IN 17 sistema de água nebulizada (mulsifyre), IN 18 controle de materiais de revestimento, IN 19 instalações elétricas de baixa tensão, IN 20 parque para armazenamentos de líquidos inflamáveis e combustíveis, IN 21 postos para reabastecimento de combustíveis (líquidos inflamáveis \& gnv), IN 22 instalação para reabastecimento de combustíveis de uso privativo, IN 23 em revisão, IN 24 eventos temporários, IN 25 rede pública de hidrantes, IN 26 revogada, IN 27 prevenção em espetáculos pirotécnicos, IN 28 brigada de incêndio, IN 29 postos de revenda de glp (prglp), IN 30 armas, munições, explosivos e fogos de artifícios, IN 31 plano de emergência ,IN 32 caldeiras e vasos de pressão, IN 33 parques aquáticos, piscinas e congêneres, IN 34 atividades agropastoris e silos, IN 35 acesso de viaturas (SANTA CATARINA. CBM, 2020).
\end{abstract}

As vistorias são realizadas de acordo com as exigências estabelecidas nas referidas INs. Após a vistoria os dados são compilados em 2 (dois) sistemas chamados de SIGAT (Sistema de Gestão da Atividade Técnica e SGI (Sistema de Gerenciamento de Infrações).

A parte formal da aplicação do poder de polícia ocorre de acordo com as exigências estabelecidas na IN 02 que regula as Infrações Administrativas no que diz respeito aos sistemas preventivos contra incêndio e pânico, a qual será objeto de análise nesse tópico.

Importante destacar que para as irregularidades observadas durante a vistoria será lavrado um documento, estabelecendo prazos. Verifica-se nesse momento a 
aplicação de um ato de vontade do estado em prol do interesse da segurança da coletividade.

Constatadas irregularidades ou infrações será lavrado auto de fiscalização ou auto de infração, conforme o caso, determinando as correções das anormalidades observadas, $O$ auto de infração refere-se a uma sanção administrativa (art. $4^{\circ}$ IN 02 CBMSC. SANTA CATARINA, 2019c).

A elaboração do auto de fiscalização firma entre o poder público e o particular a obrigação de sanar as irregularidades, o que será verificado em nova vistoria, o não cumprimento das exigências pode ensejar a aplicação de sansões administrativas.

O Auto de fiscalização representa a obrigação do responsável pela edificação em sanar as irregularidades no prazo estipulado. $O$ descumprimento da obrigação incide na aplicação das sanções legais cabíveis (art. 11, IN 02 SANTA CATARINA, 2019c).

O descumprimento do prazo gera uma infração administrativa que possibilita a emissão de um Auto de Infração, as infrações administrativas podem ser punidas com as seguintes sanções: I Advertência II - multa; III - embargo parcial ou total de obra; IV - interdição parcial ou total de imóvel; V - cassação de atestado de vistoria de funcionamento ou regularização; VI - suspensão de atestado de vistoria de funcionamento ou regularização.

Observa-se que são várias as sanções aplicáveis e concomitantemente inúmeros prazos para controlar, sendo assim o SGI (sistema de gerenciamento de infrações) possibilita um armazenamento de todos os dados desde a que a lei 16.157 de novembro de 2013 entrou em vigor.

O Corpo de Bombeiros Militar de Mafra possui registrado do SIGAT cerca de 4.368 (quatro mil trezentos e sessenta e oito) Edificações, das quais 1.000 (um mil) já receberam um auto de fiscalização (SGI). 
Gráfico 1 - Registro do Corpo de Bombeiros Militar de Mafra do SIGAT em Mafra, SC

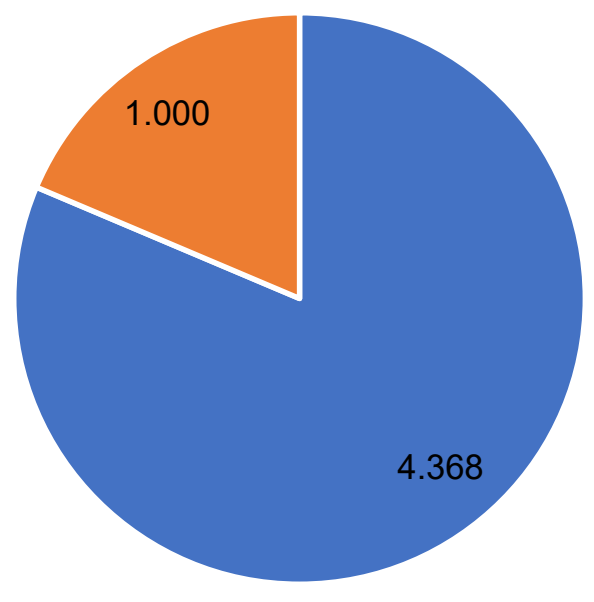

- Total de Edificações - Edificações Notificadas

Fonte: Sistema de Gestão da Atividade Técnica e Sistema de Gerenciamento de Infrações.

Analisando os referidos dados verifica-se que um número baixo de edificações firmou prazos para regularização ou sofreram algum tipo de sanção administrativa por parte do Corpo de Bombeiros Militar de Mafra.

Para as edificações constantes no rol das que já receberam notificação algumas receberam um auto de infração de Multa, sanção aplicada pelo descumprimento de prazo ou exigência quando " deixar de sanar as irregularidades no prazo estipulado em auto de fiscalização II - identificados um dos fatos descritos no inciso II e III do artigo 26; III - opuser embaraço à atuação do CBMSC" (art. 21, IN 02, SANTA CATARINA, 2019c).

As Infrações administrativas coroadas com sanções de Multa se revestem de legitimidade jurídica e nesse sentido tem se manifestado o Egrégio Tribunal de Justiça de Santa Catarina:

EMBARGOS DE DECLARAÇÃO. ART. 1.022 DO CPC. Apelação. Ação Civil Pública. Mostra Casa Nova 2012. Evento de arquitetura, decoração e paisagismo realizado nas dependências de prédio escolar já tombado pelo Patrimônio Histórico Municipal. Desobediência aos pontos assinalados pelo Corpo de Bombeiros Militar em Vistoria, dentre eles, (1) Redimensionamento das saídas de emergência e do Sistema Preventivo por Extintores; (2) a instalação de corrimãos contínuos nas escadas; (3) a sinalização de abandono do local; (4) a iluminação de emergência; e (5) o gás central canalizado. Alvará de Funcionamento indeferido. Evento que, mesmo assim, foi realizado. Visitantes expostos a risco. Responsabilização da rede de comunicação ao pagamento de indenização por dano moral 
coletivo. Insurgência da empresa multimídia. Alegada inexistência de situação grave o suficiente para causar prejuízo concreto ou de efetivo abalo moral. Admissão, porém, de que 'faltou o definitivo deferimento do alvará [...]'. Condenação mantida. '[...] O dano moral coletivo é aferível in re ipsa, ou seja, sua configuração decorre da mera constatação da prática de conduta ilícita que, de maneira injusta e intolerável, viole direitos de conteúdo extrapatrimonial da coletividade, revelando-se despicienda a demonstração de prejuízos concretos ou de efetivo abalo moral [...]' (STJ, resp 1487046/mt, rel. Min. LUIS FELIPE SALOMÃO, j. Em 28/03/2017). Pretendida readequação do importe compensatório, originalmente arbitrado em R\$ 500 mil. Possibilidade. Princípios da proporcionalidade e razoabilidade. Redefinição da monta para $\mathrm{R} \$ 50$ mil. Recurso conhecido e parcialmente provido (SANTA CATARINA. Tribunal de Justiça, 2019).

\title{
A referida demanda apresenta recurso de Embargo de Declaração
} apresentado na Ação Civil Pública demanda em face de evento Mostra Casa Nova 2012, o qual ocorreu sem autorização prévia do Corpo de Bombeiros Militar de Santa Catarina.

Nesse sentido tem se manifestado o egrégio Tribunal de Justiça de São Paulo:

\begin{abstract}
AÇÃO CIVIL PÚBLICA Obrigação de fazer atinente à adoção de providências para obter Autos de Vistoria do Corpo de Bombeiros (AVCB) em favor de prédio de escola municipal Admissibilidade Lei Complementar de Diadema $n^{\circ} 2 / 1990$, que determina às escolas equiparem e adaptarem aos sistemas de proteção e combate contra incêndios Proteção à vida dos ocupantes das edificações e áreas de risco em caso de incêndio Assunto de altíssima relevância que não abre margem para qualquer discricionariedade do poder público Redução do prazo para cumprimento da determinação judicial Legalidade da imposição de astreintes Apelação da Municipalidade não provida Apelação do Ministério Público parcialmente provida (TJSP; Apelação / Remessa Necessária 1014024-91.2018.8.26.0161; Relator (a): Fermino Magnani Filho; Órgão Julgador: $5^{\mathrm{a}}$ Câmara de Direito Público; Foro de Diadema - Vara da Fazenda Pública; Data do Julgamento: 15/06/2020; Data de Registro: 15/06/2020).
\end{abstract}

Dessa forma, verifica-se que a aplicação do Poder de Polícia pelos corpos de bombeiros militares tem se fixado como favorável nos processos judiais e recursos apresentados perante os tribunais.

Idêntica é a postura do Superior Tribunal de Justiça:

A pergunta que se faz é a seguinte: pode o Poder Judiciário imiscuir-se na Administração, impondo-lhe obrigação específica? A resposta é positiva, na medida em que se contemplam os novos rumos do Direito Administrativo. A partir da Constituição de 1988, não se pode mais tolerar o entendimento de que ao Poder Judiciário não cabe adentrar as questões internas da 
Administração, principalmente quando há carência orçamentária da municipalidade (REsp n ${ }^{\circ} 574.875 / S P$, relatora Ministra Eliane Cilmona).

O Superior Tribunal de Justiça também tem se manifestado de forma favorável e estabelece que é dever do STJ estar integrado com os assuntos discutidos relativos a administração, principalmente no que tange a recursos e segurança.

\section{CONSIDERAÇÕES FINAIS}

O presente trabalho abordou, através de um método dedutivo monográfico por meio de técnicas de pesquisa bibliográfica indireta, documentação, legislação vigente, doutrina e jurisprudência a aplicação do poder de polícia exercido pelo Corpo de Bombeiros Militar na cidade de Mafra/SC.

A fiscalização exercida pelo Corpo de Bombeiros antes da vigência da Lei $n$. 16.157 de 2013, que efetivou o poder de polícia ao CBMSC se dava de forma paliativa e as irregularidades sem solução se prolongavam no tempo. Infelizmente uma tragédia na boate Kiss, na cidade de Santa Maria/RS, foi um marco para a modernização das legislações no tocante a prevenção de incêndio e pânico.

Nesta ocasião inúmeras vidas foram ceifadas de forma trágica e os principais motivos relacionados com as mortes se referem a falhas nos sistemas preventivos necessários para a edificação onde se localizava a boate.

O CBMSC elaborou no final de 2013 e início de 2014, as Instruções Normativas para regulamentar de forma mais eficiente suas atividades desenvolvidas no tocante sistemas preventivos contra incêndio e pânico.

Observa-se que as normas sofreram alterações significativas e pode-se dizer que radicais em alguns aspectos, importante destacar que a tragédia no Rio Grande do Sul, de forma natural conscientizou a população que passou a dar maior importância para os quesitos relacionados aos sistemas preventivos.

Observa-se que na cidade de Mafra/SC, aproximadamente 1.000 (mil) edificações já foram notificadas pelo Corpo de Bombeiros Militar, ou seja, são edificações que possuem prazos firmados com a instituição e encontram-se em processo de regularização, possuem as exigências mínimas necessária para seu 
funcionamento sem colocar em risco a segurança das pessoas que ali frequentam ou habitam.

De um total de 4.368 (quatro mil trezentos e sessenta e oito) edificações cerca de $22,8 \%$ (vinte e dois virgula oito por cento) possuem processo no Sistema de Gerenciamento de Infrações, número esse que pode ser considerado pouco expressivo, ou seja a grande parte das edificações estão regularizadas, possuem instalados todos os sistemas preventivos contra incêndio e pânico necessários para proporcionar segurança para as pessoas que ali circulam ou habitam.

Cabe ressaltar, que não foi encontrado nenhum artigo publicado que abordasse de forma precisa o referido assunto, elevando assim a importância do material apresentado. Bem como proporciona um estopim para novas áreas de pesquisa no que tange ao Poder de Polícia Exercido Pelos Corpos de Bombeiros Militares.

Nesta toada, com base em todo o estudo exposto, é possível concluir que $A$ concessão do Poder de Polícia ao CBMSC exercido na cidade de Mafra/SC, tem se mostrado fundamental para regularização das edificações bem como agilizado o processo de regularização com prazos firmados e sanções aplicadas.

\section{REFERÊNCIAS}

\section{BARROSO, Luís Roberto. O direito constitucional e a efetividade de suas} normas: limites e possibilidades da constituição brasileira. 2.ed. Rio de Janeiro: Renovar, 1993.

BRASIL. Lei $\mathbf{n}^{\circ}$ 5.172, de 25 de outubro de 1966. Dispõe sobre o Sistema Tributário Nacional e institui normas gerais de direito tributário aplicáveis à União, Estados e Municípios. Disponível em: http://www.planalto.gov.br/ccivil_03/ leis/15172compilado.htm. Acesso em: 26 fev. 2020.

BRASIL. Lei 13.425 de 30 de março de 2017. Estabelece diretrizes gerais sobre medidas de prevenção e combate a incêndios e a desastres em estabelecimentos, edificações e áreas de reunião de público (Lei Kiss). Disponível em:

https://dat.cbm.sc.gov.br/index.php/pt/cidadao/legislacao. Acesso em: 26 fev. 2020.

BRASIL. Superior Tribunal de Justiça. REsp 574875 SP 2003/0145409-0. Relator: Ministra Eliana Calmon. Órgão Julgador T2 - SEGUNDA TURMA. Julgamento 15 dez. 2005. Publicado em: 06 mar. 2006. 
CARDOSO, Luiz Antônio. Prevenção de incêndio: uma retrospectiva dos primeiros anos das atividades técnicas em Santa Catarina. Florianópolis: Papa-livro, 2014.

CARVALHO FILHO, José dos Santos. Manual de direito administrativo. 33. ed. São Paulo: Atlas, 2019.

LAZZARINI, Álvaro. Estudos de direito administrativo. 2. ed. São Paulo: Revista dos Tribunais, 1999.

LENZA, Pedro. Direito constitucional esquematizado. 23. ed. São Paulo: Saraiva, 2019.

MAZZA, Alexandre. Manual de direito administrativo. 8. ed. São Paulo: Saraiva, 2018.

MEIRELLES, Hely Lopes. Direito administrativo brasileiro. 27. ed. São Paulo: Malheiros, 2002.

MELLO, Celso Antônio Bandeira de. Curso de direito administrativo. 26.ed. São Paulo: Malheiros, 2008.

NOHARA, Irene Patrícia. Direito administrativo. 9. ed. São Paulo: Atlas, 2019.

SÃO PAULO. Tribunal de Justiça. Apelação / Remessa Necessária 101402491.2018.8.26.0161. Relator: Fermino Magnani Filho; Órgão Julgador: $5^{\text {a }}$ Câmara de Direito Público; Foro de Diadema - Vara da Fazenda Pública; Data do Julgamento: 15 jun. 2020. Data de Registro: 15 jun. 2020.

SANTA CATARINA. CORPO DE BOMBEIROS MILITAR. Disponível em: https://www.cbm.sc.gov.br/ Acesso em: 26 fev. 2020.

SANTA CATARINA. CORPO DE BOMBEIROS MILITAR. Dtz Nr 26 (Diretriz Operacional padrão 26/2017): execução e fiscalização da atividade técnica pelo CBMSC. Florianópolis: CBMSC, 2017. Disponível em:

https://dat.cbm.sc.gov.br/images/arearestrita/Diretriz/DtzPOP_Nr_26CmdoG_Atual_ Pesq.pdf. Acesso em: 26 fev. 2020.

SANTA CATARINA. Decreto 1.957 de 20 de dezembro de 2013. Regulamenta a Lei $n^{\circ} 16.157$, de 2013, que dispõe sobre as normas e os requisitos mínimos para a prevenção e segurança contra incêndio e pânico e estabelece outras providências. Disponível em: https://dat.cbm.sc.gov.br/images/arearestrita/Diretriz/DtzPOP_Nr_ 26CmdoG_Atual_Pesq.pdf Acesso em: 26 fev. 2020.

SANTA CATARINA. Lei 16.157 de 07 de novembro de 2013. Dispõe sobre as normas e os requisitos mínimos para a prevenção e segurança contra incêndio e pânico e estabelece outras providências. Disponível em:

https://dat.cbm.sc.gov.br/index.php/pt/cidadao/legislacao. Acesso em 26 fev. 2020. 
SANTA CATARINA. SECRETARIA DE SEGURANÇA PÚBLICA. CORPO DE BOMBEIROS MILITAR. Normas de segurança contra incêndio: IN01-01: procedimentos administrativos: processos gerais de segurança contra incêndio e pânico: Parte 1. Florianópolis, 2019a.

SANTA CATARINA. SECRETARIA DE SEGURANÇA PÚBLICA. CORPO DE BOMBEIROS MILITAR. Normas de segurança contra incêndio: IN01-02: Procedimentos administrativos: processos gerais de segurança contra incêndio e pânico: parte 2. Florianópolis, 2019b.

SANTA CATARINA. SECRETARIA DE SEGURANÇA PÚBLICA. CORPO DE BOMBEIROS MILITAR. Normas de segurança contra incêndio: IN02: infrações administrativas. Florianópolis, 2019c.

SANTA CATARINA. Tribunal de Justiça. Embargos de Declaração: ED $0902065-$ 06.2015.8.24.0023 Capital 0902065-06.2015.8.24.0023. Relator: Luiz Fernando Boller. Florianópolis, 15 out. 2019.

Artigo recebido em: 21/08/2020

Artigo aceito em: 22/10/2020

Artigo publicado em: 02/12/2020 